\title{
Exercise and postprandial lipid metabolism
}

\author{
Adrianne E. Hardman* and Sara L. Herd \\ Human Muscle Metabolism Research Group, Loughborough University, Loughborough LEII 3TU, UK
}

Energy expenditure and fat oxidation are both profoundly increased in exercise. In absolute terms, fat oxidation is greatest during exercise of moderate intensity $(60-65 \%$ maximum $\mathrm{O}_{2}$ uptake, $\dot{V}_{\mathrm{O}_{2} \text { max }}$ ) when subjects following a mixed diet may oxidize between 0.3 and $0.7 \mathrm{~g}$ fat $/ \mathrm{min}$, representing up to $60 \%$ of energy expended (Saltin \& Astrand, 1993). Because the capacity of muscle fibres to synthesize fatty acids de novo is limited (Saggerson et al. 1992), the bulk of fatty acids has to be supplied from extracellular sources. It is likely, therefore, that postprandial lipid acquisition by muscle will be modified during and/or after exercise.

\section{Lipid substrates for skeletal muscle during exercise}

Fatty acids are available for oxidation by contracting muscle from several sources: adipose-tissue depots, via albumin-bound plasma non-esterified fatty acids (NEFA); triacylglycerol (TAG) within muscle fibres; TAG in adipose tissue located between muscle fibres; and plasma TAG-rich lipoproteins. The weight of the evidence shows that, during exercise, plasma NEFA are the most important of these, accounting, for example, for almost all fat oxidation measured in low-intensity exercise (Romijn et al. 1993). There is conflicting evidence, however, concerning the roles of intramuscular TAG and plasma TAG and almost no information on which to assess a potential contribution from adipocytes situated between muscle fibres.

Direct evidence for the hydrolysis of intramuscular TAG during exercise in man has mostly come from comparison of the TAG content of needle-biopsy samples of muscle, before and after exercise. An inherent difficulty is the extent to which the sample biopsied is representative of the exercised muscle mass; different biopsies will not have exactly the same fibre type composition and type I fibres are known to have a higher TAG content than type II fibres (Essén, 1978). There are reports of a decrease in muscle TAG concentration after exercise, varying in duration from 0.5 h (Fröberg et al. 1971; Costill et al. 1973; Essén, 1978; Hurley et al. 1986) to many hours (Fröberg \& Mossfeldt, 1971), but several studies have not found a quantitatively important decrease (Jansson \& Kaijser, 1982; Kiens et al. 1993 ) in either trained or untrained subjects (Turcotte $e t$ al.
1995). It is difficult, however, to envisage a role for intramuscular TAG other than as a substrate for energy metabolism.

A commonly-held view is that the contribution to exercise metabolism from oxidation of NEFA derived by hydrolysis of TAG-rich lipoproteins is small (van der Vusse \& Reneman, 1996), perhaps contributing between 5 and $15 \%$ of the energy derived from fat oxidation. In reality there is a paucity of information, and rather a strong case, theoretically, for its re-examination. TAG-rich lipoproteins represent a potentially-rich source of fatty acids for the working muscle, particularly after consumption of a fatcontaining meal when chylomicron concentrations are high. Also, because of the insulin response to co-ingested carbohydrate, plasma concentrations of NEFA fall postprandially and this could increase the contribution of fatty acids from lipoprotein-TAG. Finally, high rates of fatty acid oxidation in contracting muscle may enhance the rate of removal of NEFA from the site of TAG hydrolysis, decreasing substrate inhibition of lipoprotein lipase $(E C$ 3.1.1.34; LPL) and favouring hydrolysis of the TAG core of lipoprotein.

Prolonged exercise is associated with a small decrease in the plasma concentration of TAG, which could reflect use of VLDL-TAG as a fuel for exercise (Nagel et al. 1989). It could be attributed equally, however, to decreased hepatic secretion of VLDL, secondary to reduced blood flow. A number of studies have measured plasma TAG uptake by muscle during exercise in fasted subjects. Several have found no significant extraction (Havel et al. 1967; Kaijser \& Rössner, 1975; Olsson et al. 1975). However, Kiens et al. (1993) estimated total degradation of VLDL-TAG (from integrated areas under TAG concentration $v$. time curves multiplied by plasma flow) and concluded that this could cover a major part of fat oxidation during exercise, despite the fact that there was no consistently detectable arteriovenous difference for TAG.

Surprisingly, there are few reports describing the extent to which muscle takes up chylomicron TAG in man. In dogs, chylomicron TAG uptake by muscle has been reported to increase significantly during exercise, with a complementary decrease in uptake by adipose tissue (Terjung et al. 1983); if totally oxidized, the TAG-derived fatty acids could account for approximately $11 \%$ of the

\footnotetext{
Abbreviations: LPL, lipoprotein lipase; NEFA, non-esterified fatty acids; TAG, triacylglycerols; $\dot{V}_{\mathrm{O}_{2} \max }$, maximum $\mathrm{O}_{2}$ uptake

*Corresponding author: Dr A. E. Hardman, fax + 44 (0)1509 223971, email a.e.hardman@lboro.ac.uk
} 
total $\mathrm{O}_{2}$ consumption during the exercise. In one study of human volunteers no net extraction of TAG across working muscle in the fed state was detected, although there was indirect evidence for this through production of HDL (Ruys $e t$ al. 1989). Later study of substrate exchange during $1 \mathrm{~h}$ of forearm exercise found that, in contrast to the post-absorptive state, muscle extracted TAG when exercise was performed $3 \mathrm{~h}$ after consumption of a meal containing both fat and carbohydrate (Griffiths et al. 1994). In the latter study, however, isometric contractions were performed intermittently and the measured muscle uptake of TAG would incorporate 'recovery' as well as contraction phases. Thus, the evidence concerning the contribution of TAG-derived fatty acids to muscle metabolism during exercise is equivocal and more studies of the postprandial state are needed.

TAG-rich lipoproteins may not play a major role in supplying fatty acids to skeletal muscle during exercise but they are clearly important in replenishing muscle TAG after exercise. Chylomicrons and VLDL are cleared by a common saturable pathway (Björkengren et al. 1996), the rate-limiting step of which is hydrolysis of core TAG by LPL. Most tissues express LPL but its activity is highest in the myocardium, adipose tissue and skeletal muscle (besides lactating mammary gland). Because of their mass, adipose tissue and muscle are probably the major sites of TAG removal but their relative importance remains a matter of debate.

Early studies using nephelometry to assess plasma turbidity found that muscle cleared $50 \%$ of a fat emulsion infused intravenously, compared with $13 \%$ by adipose tissue (Rössner, 1974). This conclusion is not supported, however, by recent findings. Chylomicron uptake has been measured across the splanchnic bed (reflecting uptake into visceral fat) and across the leg (Nguyen et al. 1996). These workers found that uptake into the splanchnic bed accounted for 70 and $20 \%$ of meal TAG disappearance in men and women respectively. By comparison, the uptake by the legs was small (12 and 8\%). Nguyen et al. (1996) interpreted leg uptake as 'presumably in (leg) adipose tissue', ignoring the possibility of a contribution from skeletal muscle. Arterio-venous differences for chylomicron TAG and VLDL-TAG have also been measured across subcutaneous abdominal adipose tissue and forearm muscle after consumption of a mixed meal (Potts et al. 1991b). Fractional extraction of chylomicron TAG over a $6 \mathrm{~h}$ period was threefold lower in muscle than in adipose tissue. Neither of these studies, however, gave information about the exercise status of the subjects, long or short term, and both could be relevant because recent exercise is probably the most important determinant of muscle TAG concentration and, hence, the need for replenishment.

Long-term regular exercise has considerable potential to enhance muscle TAG uptake via (1) increases in muscle mass and (2) structural changes in its microcirculation. Endurance-trained individuals (Ingjer, 1979) have more capillaries around each muscle fibre and more capillaries per unit cross-sectional area of muscle. The implication of this for LPL activity has been elegantly demonstrated; in men who trained one leg but not the other at $65 \% \dot{V}_{\mathrm{O}_{2} \max }$ for 8 weeks, capillarization was $20 \%$ greater in muscle from the trained leg than from the untrained contralateral leg, with $35-46 \%$ higher LPL activity (Kiens \& Lithell,

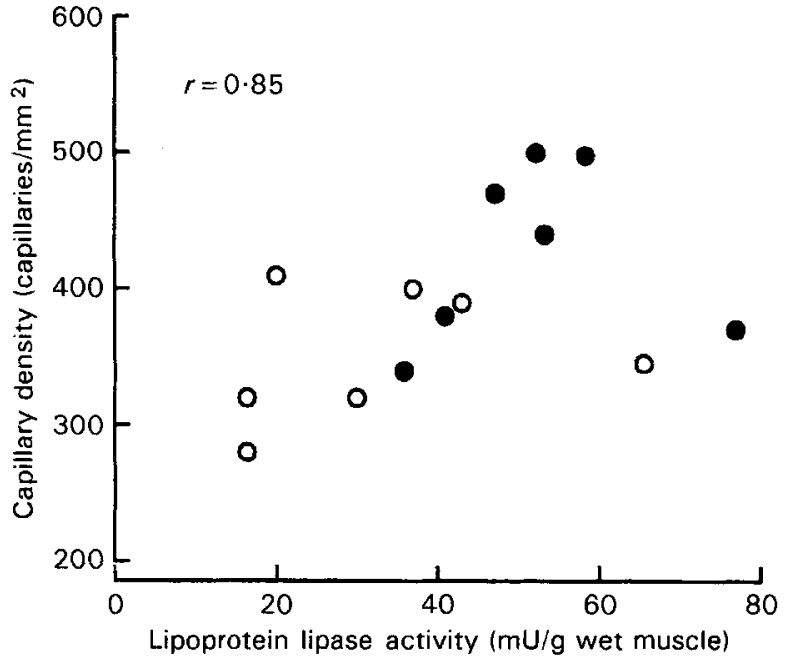

Fig. 1. Relationship between lipoprotein lipase (EC 3.1.1.34) activity and capillary density measured in the same needle-biopsy sample of vastus lateralis after 8 weeks of training of the knee extensors of one leg but not the other. ( $\bullet$ ), Endurance-trained muscle; $(0)$, untrained muscle. $1 \mathrm{mU}$ enzyme activity was defined as $1 \mathrm{nmol}$ fatty acid released per min. (After Kiens \& Lithell, 1989.)

1989). Moreover, muscle LPL activity was related to capillary density (Fig. 1). The acquisition of fatty acids from TAG-rich lipoproteins is thus facilitated in trained muscle. This ties in persuasively with the enhanced utilization of muscle TAG reported for trained individuals (Hurley et al. 1986) and perhaps also with evidence (in the rat) of a close coupling between the size of muscle TAG stores and uptake of plasma TAG-derived fatty acids (Tan et al. 1977).

\section{Influence of training on postprandial lipaemia}

Endurance-trained individuals exhibit plasma concentrations of HDL-cholesterol $20-30 \%$ higher than those of their sedentary counterparts, as well as low plasma concentrations of TAG in the fasted state (for review, see Durstine \& Haskell, 1994). Attention has focused on HDL-cholesterol levels but these may be a metabolic marker for their enhanced metabolic capacity for TAG degradation. The reason is that high concentrations of TAG-rich lipoproteins provide increased opportunity for exchange of TAG with cholesteryl esters from $\mathrm{HDL}$ and as a consequence the cholesterol measured in HDL decreases (Patsch et al. 1992).

\section{Cross-sectional studies}

An individual's metabolic capacity for TAG is challenged during the postprandial period (or some model for this) when concentrations of TAG-rich lipoproteins are at their highest. A number of studies have compared trained people with untrained or sedentary controls, using different methodologies, i.e. oral fat tolerance tests (Cohen et al. 1989; Merrill et al. 1989; Hartung et al. 1993; Isherwood, 1996), intravenous infusion of lipid emulsion (Björntorp et al. 1972; Ericsson et al. 1982; Sady et al. 1988; Cohen et al. 1989; Podl et al. 1994) and, in one case (Cohen et al. 1989), duodenal perfusion with lipid emulsion. In the 
earliest of these, middle-aged men who trained and competed in orienteering and cross-country skiing showed a high TAG removal rate, compared with controls, although rates in the trained men were not exceptional in relation to controls with similarly low fasting plasma TAG concentrations (Björntorp et al. 1972). Confirmatory evidence of faster TAG removal in young athletes than in controls matched for height and weight was published 10 years later (Ericsson et al. 1982). Subsequent studies have also found enhanced TAG clearance rates in male (Sady et al. 1988) and female (Podl et al. 1994) endurance athletes.

Studies using an oral fat challenge (40-140 g) have produced broadly similar findings, i.e. the magnitude of postprandial lipaemia (measured as the area under the plasma TAG concentration $v$. time curve over $8 \mathrm{~h}$ ) has been found to be lower in endurance-trained men than in controls (Cohen et al. 1989; Merrill et al. 1989; Hartung et al. 1993; Isherwood, 1996). Patients with coronary artery disease who had participated in a rehabilitation programme ( $\geq 3$ months) also had a $28 \%$ lower lipaemic response than men with similar disease status who had elected not to follow the programme (Yanes et al. 1989), suggesting that exercise may improve postprandial lipaemia even in individuals who are symptomatic for atherosclerotic disease. However, aspects of the rehabilitation programme other than the exercise could have influenced these findings. For example, there was clearly a difference in dietary practice, patients following the rehabilitation programme consumed less fat ( $28 v .41 \%$ daily energy intake) and more carbohydrate (55 v. $39 \%$ daily energy intake) than the comparison group.

Several potentially confounding issues need to be considered. First, because chylomicrons and VLDL are cleared by a common pathway, levels of postprandial lipaemia are related to the size of the endogenous TAG pool (O'Meara et al. 1992). In several of the cross-sectional studies described, TAG concentrations in the fasted state were lower in the exercise groups (Björntorp et al. 1972; Ericsson et al. 1982; Sady et al. 1988; Hartung et al. 1993). Two studies have attempted to control for this difference by matching athletes and controls for fasting TAG concentration; even in these circumstances, chylomicron half-life was lower ( 3 v. $4 \mathrm{~min}$; Cohen et al. 1989) and the area under the plasma TAG concentration $v$. time curve above the fasting level was lower (by $45 \%$ ) in athletes (Merrill et al. 1989), showing that differences between groups could not be attributed entirely to the fasting TAG pool size.

Second, athletes have different dietary practices from sedentary controls; typically, energy intake is greater, with a larger proportion of total energy derived from carbohydrate (Walker, 1986). This may influence indices of TAG clearance because high-carbohydrate diets up-regulate, and high-fat diets down-regulate, the activity of LPL in adipose tissue (Eckel, 1989), with opposite effects in skeletal muscle (Jacobs et al. 1982). The implications for comparisons between athletes and others cannot be stated, however, because of the complexity of these influences and their potential interactions with co-existing differences in body composition.

Finally, differences in muscle fibre population could contribute to the high metabolic capacity of athletes for
TAG because, based on animal studies, LPL activity is highest in type I fibres (Borensztajn et al. 1975). Endurance athletes typically possess a larger proportion of these highly oxidative fibres (Costill et al. 1976), which could enhance their whole-body response to a TAG challenge. Indeed, after a mixed diet, muscle LPL activity has been reported to be directly related $(r 0.95)$ to the proportion of type I fibres in needle-biopsy samples of human skeletal muscle (Jacobs et al. 1982).

Overall, the evidence from cross-sectional studies is that postprandial lipaemia following an oral fat challenge is 27$59 \%$ lower, and removal rates of intravenous TAG 26$92 \%$ higher, in endurance-trained individuals (middle-aged men as well as young men and women) than in untrained or sedentary controls. Trained people exhibit these characteristics despite their low levels of body fat, the tissue with highest LPL activity per unit mass, suggesting that the quantity and/or the quality of their skeletal muscle is important. In the 'real-life' situation of normal meals, related characteristics of the trained state probably contribute. These would include, for example, improvements in insulin sensitivity, with implications for the integration of postprandial responses; even, speculatively, enhancement of the insulin-stimulated increase in muscle blood flow (Ebeling et al. 1993).

One final point should be made. Individual sessions of exercise can profoundly influence fasting and postprandial TAG metabolism (see pp. 66-67). Measures of fat tolerance in cross-sectional studies have often been made in reasonably close proximity to a training session, the interval between training and testing being reported as, for example, 'about 12 h' (Björntorp et al. 1972), '1 d' (Merrill et al, 1989; Isherwood, 1996), and 'at least 24 h' (Sady et al. 1988). Other investigators have allowed subjects to follow their customary training regimen on the day before the test (Cohen et al. 1989; Podl et al. 1994); yet others provide no information. Athletes will invariably train unless specifically requested not to do so, because this is their habit. Consequently, although these findings describe accurately the good fat tolerance in trained people in everyday life, they do not permit a conclusion to be drawn on whether long-term adaptations to training exert an influence on postprandial lipaemia beyond the effects of a single session of exercise.

\section{Intervention studies}

Early studies described the influence of 8-10 weeks of training on postprandial TAG concentrations (Altekruse \& Wilmore, 1973) and the optical density of serum samples (Zauner \& Benson, 1977). The decrease in lipaemia was of the same order in both studies $(24 \%)$, although this was not statistically significant in the latter study of men selected for their abnormally high response to an oral fat tolerance test. Patsch et al. (1983) described the postprandial responses to dietary fat for two men during a 4-year training period. Full data were presented for one subject only, in whom postprandial lipaemia decreased with training by $95 \%$, with an increase in $\mathrm{HDL}_{2}$-cholesterol.

In a detailed study of six healthy men before and after 7 weeks of jogging training, Weintraub et al. (1989) 
controlled diet carefully to ensure that subjects did not lose body weight. Based on the vitamin A-fat loading test, chylomicron retinyl palmitate levels were reduced by $37 \%$ with training. There was no relationship between chylomicron lipaemia and HDL-cholesterol, the authors suggesting that a longer period of training may be needed before this complementary change is evident. (This is consistent with the case study referred to earlier where the first sign of an increase in HDL-cholesterol was after 7 months.) A longer study, with 32 and 48 weeks of training, found an increase (13\%) in HDL-cholesterol alongside a $49 \%$ improvement in the capability to clear an intravenous fat load (Thompson et al. 1988). The latter finding, alongside training-induced increases in heparin-releasable LPL activity (Thompson et al. 1988; Weintraub et al. 1989), suggests that improved TAG clearance, as opposed to decreased appearance, is responsible for these improvements in the plasma TAG response to dietary fat.

Two studies (both randomly controlled) report conflicting findings of no significant improvement in fat tolerance with training. In one, men with primary hyperlipidaemia ( $n$ 17 , type IV, high fasting TAG; $\boldsymbol{n} 6$, type Illb, high total and LDL-cholesterol) were studied using an intravenous fat challenge (Wirth et al. 1985). Clearance rates for TAG improved by an average of $8 \%$ in the men who trained but did not differ significantly after training from rates measured in controls. Improvements could have been restrained by the patients' pathologies, but as seven of nine patients who trained showed increased clearance, the low power to detect a change may be a factor. In a more recent study, healthy middle-aged women (thirteen exercisers, thirteen controls) trained over 12 weeks by brisk walking (Aldred et al. 1995). Despite clear improvements in endurance fitness there was no change in the plasma TAG response to an oral fat load. One possibility is that the intensity of training, i.e. approximately $60 \% \vec{V}_{\mathrm{O}_{2} \max }$, was insufficient to stimulate morphological changes in skeletal muscle. It is noteworthy, however, that the two studies with 'negative' findings were specifically designed to exclude effects of recent exercise; subjects were studied between 48 and $72 \mathrm{~h}$ after (Wirth et al. 1985) and $48 \mathrm{~h}$ after (Aldred $e t$ al. 1995) the last training session, which raises again the issue of the timing of post-training assessments.

A preliminary study in our laboratory found a marked increase in postprandial lipaemia in endurance athletes who refrained from exercise for $6 \mathrm{~d}$, most of this increase occurring in the first $60 \mathrm{~h}$ (Lawrence et al. 1997). On this evidence, effects of a recent training session would have contributed to the improvement in fat tolerance reported in the intervention study by Thompson et al. (1988) because post-training measurements were made only $10 \mathrm{~h}$ after the last training session. Effects of training on the findings of other studies where measurements were made $36 \mathrm{~h}$ and $4 \mathrm{~d}$ respectively, after athletes' last exercise are less likely (Weintraub et al. 1989; Drexel et al. 1992). In the latter study, however, a combined intervention of diet restriction and exercise was employed so the findings are not directly comparable.

There are some indications in these findings of potential mechanisms; the lower lipaemic response after training appears to reflect mainly differences in chylomicron levels
(Weintraub et al. 1989; Drexel et al. 1992), which might be expected if training increases LPL activity and chylomicrons are the preferred substrate for LPL (Potts et al. 1991a). This suggestion is supported by the 'dramatic' effect on chylomicron and chylomicron remnant metabolism when trained men interrupt their training for 2 to 3 weeks (Mankowitz et al. 1992); de-training increased the areas under the plasma concentration $v$. time curves by 41 and $37 \%$ respectively.

\section{Effects of single exercise sessions}

It has been known since the early 1960s that a session of exercise diminishes postprandial lipaemia. For example, Cohen \& Goldberg (1960) examined the effect of a $10 \mathrm{~km}$ walk on plasma turbidity during the hours following a highfat meal; the lower turbidity during the exercise trial was attributed to improved clearance of dietary fat. Plasma turbidity was also lower in patients who were ambulatory after a fatty meal than in those who were confined to bed (McDonald \& Fullerton, 1960). In the first study to measure (serum) TAG directly, forty army recruits were divided into two groups, one of whom marched $16 \mathrm{~km}$ after consuming a fatty meal (Nikkilä \& Konttinen, 1962). The control group rested during this period. Serum TAG concentrations were significantly lower in those who marched than in those who rested. These findings appear to conflict with the view (discussed previously) that muscle does not increase its uptake of TAG during exercise. Exercise decreases splanchnic blood flow (Rowell, 1993), however, and rates of appearance of exogenous TAG could be lower during exercise, contributing to the decrease in serum TAG concentration (or turbidity).

The effect of exercise on postprandial lipaemia has subsequently been examined in laboratory conditions. For example, postprandial TAG concentrations at 4,6 and $8 \mathrm{~h}$ after consuming a high-fat breakfast were higher when men (n 6) had exercised at $75 \% \dot{V}_{\mathrm{O}_{2} \max }$ for $30 \mathrm{~min}$, starting $1 \mathrm{~h}$ after the meal, than in a rested control trial (Klein et al. 1992). A similar approach (a high-fat meal followed by exercise or rest in a repeated-measures design) has been employed to study the effects of cycling (Schlierf et al. 1987) and treadmill walking (Hardman \& Aldred, 1995). In both studies, subjects exercised at $40 \% \dot{V}_{\mathrm{O}_{2} \max }$ for $90 \mathrm{~min}$, starting $1.5 \mathrm{~h}$ after the test meal. Postprandial lipaemia was lower in the exercise trial by 34 and $24 \%$ respectively (Schlierf et al. 1987; Hardman \& Aldred, 1995). However, inspection of the TAG responses shows that most of, or all, this difference was evident during the period of recovery after exercise. This ties in with the finding that exogenous TAG was taken up in resting forearm muscle, with no increase during exercise (Kaijser \& Rössner, 1975). Exercise influences postprandial intestinal activity (Soffer et al. 1991), however, and the findings of studies where exercise is performed during the postprandial period may be influenced by altered gut function. For this reason and because exercise-induced changes in LPL activity appear to be delayed, studies examining fat tolerance some hours after a session of exercise provide a clearer picture of exercise-induced changes in postprandial lipid metabolism. 
Fasting TAG concentrations are reduced the day after prolonged exercise, alongside increases in LPL activity measured in post-heparin plasma (Kantor et al. 1984). It might be expected, therefore, that the plasma TAG response to dietary fat consumed the day after exercise would also be decreased. For example, in one study, young adults walked for $2 \mathrm{~h}$ at about $40 \%$ of $\dot{V}_{\mathrm{O}_{2} \max }$ in the afternoon and their fat tolerance was tested the following morning (Aldred et al. 1994). Postprandial lipaemia (6 h area under the plasma TAG concentration $v$. time curve after a high-fat meal) was nearly one-third lower than that for a no-exercise control trial. In contrast, Cohen et al. (1989) found little effect on lipaemia in sedentary men who performed $1 \mathrm{~h}$ of exercise $12 \mathrm{~h}$ before an oral fat tolerance test. This could reflect the lower exercise energy expenditure in the latter study. The energy expended during exercise seems to be a determinant of its effects on lipaemia (Fig. 2); sessions of moderate- or low-intensity exercise of equivalent energy expenditure $(1.5 \mathrm{~h}$ at $60 \%$ $\dot{V}_{\mathrm{O}_{2} \max } v .3 \mathrm{~h}$ at $30 \% V_{\mathrm{O}_{2} \max }$ ) resulted in identical decreases in lipaemia (Tsetsonis \& Hardman, 1996).

The evidence points to enhanced plasma clearance of TAG-rich lipoproteins as the major determinant of exercise-induced decreases in postprandial lipaemia. For example, in male distance runners, clearance of intravenous fat was $76 \%$ greater the morning after a marathon run than when measured $24 \mathrm{~h}$ before the race (Sady et al. 1986). Fasting TAG levels were reduced by $26 \%$ and plasma postheparin LPL activity increased by $46 \%$. Other studies report increases of 22 and $66 \%$ in removal rates of intravenous fat administered the morning after $3 \mathrm{~h}$ exercise sessions (Dufaux et al. 1981; Annuzzi et al. 1987). Moreover, in the studies of the plasma TAG response described previously (Aldred et al. 1994; Tsetsonis \& Hardman, 1996; Tsetsonis et al. 1997), the long interval

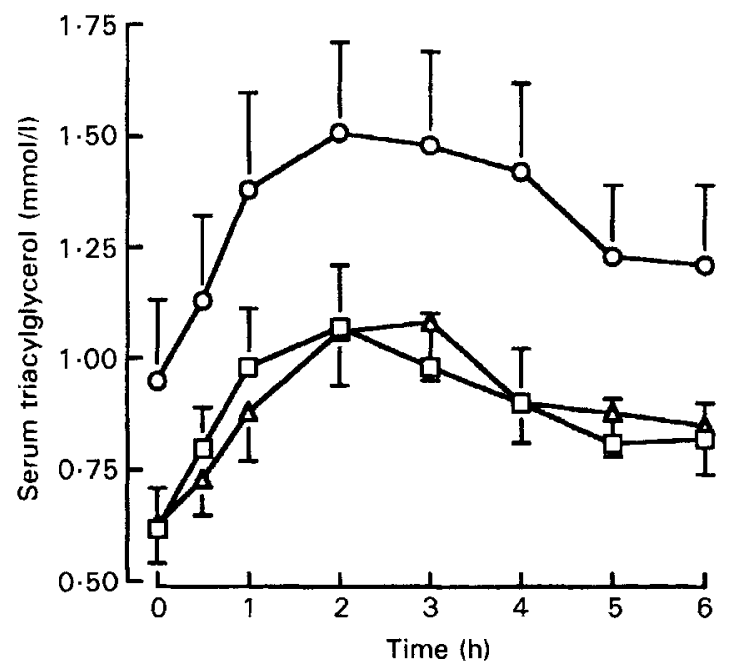

Fig. 2. Postprandial plasma triacyiglycerol response to a high-fat meal consumed the morning after: a day of minimal activity (control; - - ) ; walking for $3 \mathrm{~h}$ at $30 \%$ maximum $\mathrm{O}_{2}$ uptake (low intensity; $\left(-\square-\right.$ ); and after walking for $1.5 \mathrm{~h}$ at $60 \%$ maximum $\mathrm{O}_{2}$ uptake (moderate intensity; $-\triangle-$ ). Values are means with their standard errors represented by vertical bars for nine young adults (five men, four women). (Reprinted, with permission, from Tsetsonis \& Hardman, 1996.) between the end of exercise and assessment of postprandial lipaemia makes an effect on chylomicron appearance rate an unlikely explanation for the lower plasma TAG levels. In all these studies, fasting and postprandial plasma NEFA concentrations were higher the morning after exercise than after $1 \mathrm{~d}$ of minimal activity; as substrate delivery to the liver is the major determinant of VLDL secretion (Sniderman \& Cianflone, 1993), this would not be consistent with decreased hepatic secretion of these lipoproteins after exercise.

Supporting, although indirect, evidence comes from an examination of the effect of previous exercise on postprandial substrate metabolism in middle-aged women. When a high-fat mixed meal was ingested the morning after exercise, the women oxidized more fat than they did during a control trial, regardless of their training status (Tsetsonis et al. 1997). This is also consistent with increased TAG uptake into muscle. It is not known, however, whether or not the recently-ingested fat was the source of the additional fat oxidized.

\section{Role of lipoprotein lipase}

Although the mechanisms by which exercise mitigates postprandial lipaemia are not well understood, effects on LPL activity, the 'metabolic gatekeeper' for lipid energy storage, appear to play a key role.

Post-heparin plasma LPL activity has been reported to be higher in endurance-trained individuals than in inactive controls (Kantor et al. 1987; Podl et al. 1994; Isherwood, 1996). This reflects increased activity in skeletal muscle (Nikkilä et al. 1978), but there are also reports of higher activity in adipose tissue (Nikkilä et al. 1978) and of a positive relationship between adipose-tissue LPL activity and indices of training volume (Nikkilä et al. 1978; Marniemi et al. 1980). These findings on adipose tissue do not fit well, however, with other evidence. For example, a 2-week de-training period in athletes resulted in decreased LPL activity in muscle with parallel increases in adipose tissue (Simsolo et al. 1993); and a short period (5-13 d) of exercise in sedentary people resulted in a $35 \%$ increase in LPL activity in muscle, with no change in activity in subcutaneous adipose tissue (Seip et al. 1995). The latter findings seem biologically plausible, with complementary changes in LPL activity partitioning more lipoprotein-TAG into muscle for oxidation in the trained state. Whatever the site(s) of the increased LPL activity, its functional significance is clear from the positive relationships between plasma LPL activity and clearance rate in an intravenous fat tolerance test in male (Sady et al. 1988) and female (Podl et al. 1994) runners (Spearman's rank order correlation coefficients 0.74 and 0.61 respectively).

Focusing on skeletal muscle, intervention studies have largely confirmed the findings of cross-sectional studies. After training periods of 7,14 or 15 weeks, the corresponding increases in plasma LPL activity were 16 (Weintraub et al. 1989), 19 (Thompson et al. 1988) and $33 \%$ (Peltonen et al. 1981). More recently, an $80 \%$ increase in plasma LPL was observed when obese women followed an exercise programme for 6 months (Lamarche 
et al. 1993); no parallel changes in body weight or composition occurred and these variables were unrelated to total plasma LPL activity, suggesting that the increase might be attributable to changes in enzyme activity in some other tissue, presumably muscle.

As mentioned previously, the increase in muscle LPL activity with training could be related to improvements in the microcirculation. A period of 8 weeks of cycleergometer training resulted in a $19 \%$ increase in capillary density accompanied by an approximately $50 \%$ increase in muscle LPL activity (Svedenhag et al. 1983). No relationship was found between these two variables, but this may be because they were determined in different biopsy samples. Where measurements have been made in the same sample (Kiens \& Lithell, 1989) a rather close relationship was evident, as mentioned earlier and shown in Fig. 1. In the latter study, uptake at rest of VLDL-TAG by trained muscle was markedly greater than that by untrained muscle.

Thus, trained muscle is well-adapted to the utilization of lipoprotein-TAG; its extensive capillary network provides more binding sites for LPL, closer proximity of myocytes to capillaries will improve diffusion conditions, and increased capacity for $\beta$-oxidation may mean more entrapment of the fatty acid products of hydrolysis. These characteristics are likely to be restricted to endurancetrained muscle; capillarization is not enhanced to the same degree in sprint-trained athletes (Tesch et al. 1984) who also exhibit lower LPL activity (Nikkilä et al. 1978) and probably a higher lipaemic response to dietary fat than endurance-trained athletes (Lee et al. 1993).

Evidence of a relationship between capillarization and LPL activity suggests that the link is long-term structural adaptations in muscle. However, an increase in muscle LPL activity seems to occur during the first 2 weeks of training (Seip et al. 1995), with a rapid loss on de-training (Simsolo et al. 1993). These findings suggest that the increase in enzyme activity may partly be a response to the very early stages of training, perhaps even to a single exercise session.

Studies in human subjects have shown striking increases of 46 (Sady et al. 1986) and 74\% (Kantor et al. 1984) in plasma LPL activity measured $18 \mathrm{~h}$ after prolonged exercise lasting several hours, and smaller increases after more modest exercise (Kantor et al. 1987). There may also be a stimulus to adipose-tissue LPL activity; this was increased by $20 \%$ in well-trained men who ran $20 \mathrm{~km}$, but the increase in muscle LPL activity was greater (112\%; Taskinen et al. 1980). An increase in adipose-tissue LPL measured immediately after $1 \mathrm{~h}$ of exhaustive cycling has also been reported, but in this case with no change in activity in muscle (Lithell et al. 1979a). Subjects of this study were in the fed state, however, and results from animal studies suggest that food intake blunts the exerciseinduced increase of muscle LPL activity (Nikkilä, 1987).

LPL activity in skeletal muscle has been reported to be profoundly increased (by 200-240\%) when measured after intense exercise (Lithell et al. 1979b, 1981, 1984). In later studies using one-leg knee-extension exercise, findings were less clear (Kiens \& Lithell, 1989; Kiens et al. 1989). When measured immediately after either 1 or $2 \mathrm{~h}$ of kneeextension exercise, muscle LPL activity was unchanged from that at rest; an increase of $60 \%$ was found $4 \mathrm{~h}$, but not $8 \mathrm{~h}$, after exercise. One explanation for these apparently conflicting findings may be that knee-extension exercise, unlike whole-body exercise, evokes little catecholamine response. Catecholamines increase cAMP levels, which leads in turn to activation of LPL (Newsholme \& Leech, 1994). There is some evidence supporting this explanation; in soldiers taking part in a $10 \mathrm{~d}$ mountain expedition, exercise-induced increases in muscle LPL activity and urinary excretion of adrenaline were strongly related, the latter accounting for more than $70 \%$ of the variance in LPL activity (Lithell et al. 1981). The absence during single-leg knee-extension exercise of the hormonal changes which accompany exercise with large muscle groups may diminish use of endogenous TAG by muscle, with a corresponding increase in reliance on blood-borne lipid substrates (Kiens et al. 1993) and a reduced need for replenishment of muscle $\mathrm{TAG}$.

There is also new evidence that some of the confusion regarding exercise-induced changes in skeletal-muscle LPL activity derives from differences in the timing of biopsies in which enzyme activity is measured. A single session of moderate exercise $\left(85-90 \mathrm{~min}\right.$ at $\left.65 \% \dot{V}_{\mathrm{O}_{2} \max }\right)$ resulted in an increase in LPL mRNA, with increases in LPL protein mass following this message (Seip et al. 1997); LPL mass was unchanged directly after exercise, but was $53 \%$ higher after $4 \mathrm{~h}$ and $93 \%$ higher after $8 \mathrm{~h}$, with indications that this rise continued after the observation period. These effects were transient, however, and by $20 \mathrm{~h}$ had dissipated. Thus, the maximal increase in muscle LPL activity is probably somewhere between 8 and $20 \mathrm{~h}$ after exercise. No comparable information is available on exercise-induced changes in adipose tissue.

Finally, mention should be made of the interactions between exercise and training and insulin sensitivity and their implications for postprandial TAG disposition. First, regulation of LPL activity is tissue specific; insulin stimulates enzyme activity in adipose tissue with opposing, although weaker, effects in skeletal muscle (Farese et al. 1991). Second, these effects differ in non-exercised muscle and in muscle which has recently been exercised (Kiens $e t$ al. 1989); insulin decreases LPL activity in non-exercised muscle but this influence is over-ridden in exercised muscle by some other local, exercise-related effect. Third, in nonexercised muscle LPL activity covaries with insulin sensitivity (Kiens et al. 1989). These issues are made more complex by the influence of training on insulin sensitivity in muscle. The enhanced sensitivity has been described as a 'genuine effect of training, but short-lived' (Dela et al. 1992).

These findings are important. They lead us to question how meaningful intravenous tolerance tests are, because of the absence of an insulin response; they demonstrate the need for clear thinking and careful study design in respect of recent exercise sessions; they underscore the need for whole-body studies in human volunteers consuming 'normal' meals containing a mixture of macronutrients; they show that the habitual physical activity levels of such volunteers will influence the outcome. An example of the latter point comes from a study which compared the effect of walking for $1.5 \mathrm{~h}$ at $60 \% \dot{V}_{\mathrm{O}_{2} \max }$ on the lipaemic and 


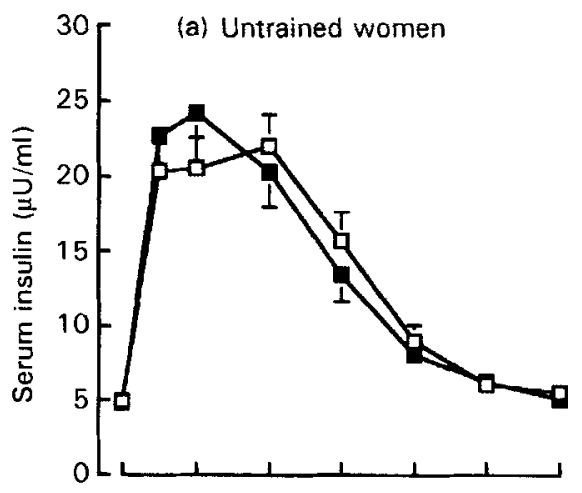

(b) Endurance-trained women
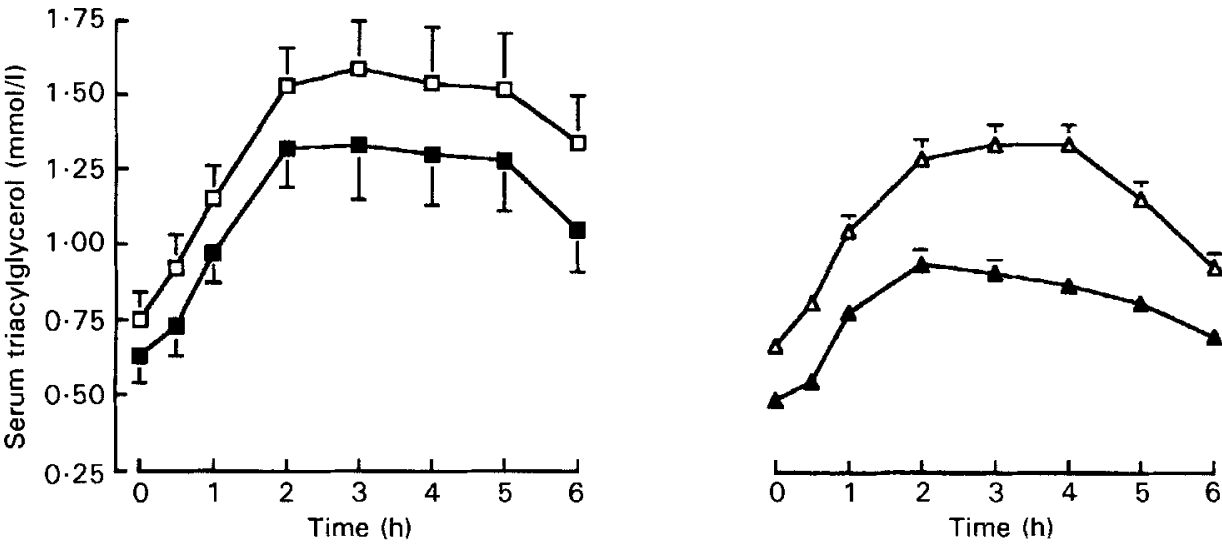

Fig. 3. Postprandial serum triacylglycerol concentrations after consumption of a high-fat meal $(1.70 \mathrm{~g}$ fat, $1.65 \mathrm{~g}$ carbohydrate, $0.25 \mathrm{~g}$ protein $/ \mathrm{kg}$ fat-free mass) the morning after $1 \mathrm{~d}$ of minimal activity (control trial; $\square, \Delta$ ) and the morning after walking for $1.5 \mathrm{~h}$ at $60 \%$ maximal $\mathrm{O}_{2}$ uptake (exercise trial; $\mathbf{E}, \Delta$ ) in middle-aged women. (a) Untrained women $(n 13)$ who ingested, on average, $75.8 \mathrm{~g}$ fat, $73.7 \mathrm{~g}$ carbohydrate, $11.2 \mathrm{~g}$ protein; (b) endurance-trained women $(n 9)$ who ingested, on average, $77.0 \mathrm{~g}$ fat, $75 \mathrm{~g}$ carbohydrate, $11.4 \mathrm{~g}$ protein. Values are means with their standard errors represented by vertical bars. (Reprinted, with permission, from Tsetsonis et al. 1997.)

insulinaemic responses to a high-fat mixed meal in endurance-trained and untrained women (Tsetsonis et al. 1997). Both groups showed a reduction in lipaemia after exercise (greater in the trained women, i.e. $28 v .17 \%$ ) but only the trained women showed lower insulinaemia (Fig. $3)$.

\section{Conclusion}

Exercise exerts a potent influence on postprandial lipid fluxes, altering lipid disposition and increasing lipid oxidation. Endurance-trained individuals exhibit low levels of postprandial lipaemia which appear to reflect enhanced uptake of TAG-rich lipoproteins. This could derive from the high level of LPL activity in their large, capillary-dense muscle mass, but the possibility exists also of increased activity of this enzyme in adipose tissue. The low lipaemic response of athletes increases rapidly, however, after a few days without exercise. Short-term effects of individual exercise sessions are, therefore, also important determinants of postprandial lipaemia. These are probably mediated through delayed effects on the activity of LPL in muscle during the hours following exercise.

Repeated episodes of exaggerated postprandial lipaemia constitute an atherogenic stimulus. This is because prolonged residence in the circulation of TAG-rich lipoproteins leads to a depletion of HDL-cholesterol and a preponderance of small, dense LDL, a combination known as the atherogenic lipoprotein phenotype (Austin et al. 1990). Regular, frequent exercise will exert a restraining influence on the postprandial rise in plasma TAG concentrations, with the possibility of a reduction in this aspect of the risk of atherosclerosis. The indications are that moderate amounts and intensities of exercise may be effective, provided a reasonable amount of energy is expended on most days.

\section{Acknowledgement}

S.L.H. was the holder of a studentship from the British Heart Foundation who also support A.E.H.'s research. The authors thank their colleagues who have contributed to this work. 


\section{References}

Aldred HE, Hardman AE \& Taylor S (1995) Influence of 12 weeks of training by brisk walking on postprandial lipemia and insulinemia in sedentary middle-aged women. Metabolism 44, 390-397.

Aldred HE, Perry I \& Hardman AE (1994) The effect of a single bout of brisk walking on postprandial lipemia in normolipidemic young adults. Metabolism 43, 836-841.

Altekruse EB \& Wilmore JH (1973) Changes in blood chemistries following a controlled exercise program. Journal of Occupational Medicine 15, 110-113.

Annuzzi G, Jansson E, Kaijser L, Holmquist L \& Carlson LA (1987) Increased removal rate of exogenous triglycerides after prolonged exercise in man: time course and effect of exercise duration. Metabolism 36, 438-443.

Austin MA, King MC, Vranizan KM \& Krauss RM (1990) Atherogenic lipoprotein phenotype: A proposed genetic marker for coronary heart disease risk. Circulation 82, 495-506.

Björkegren J, Packard CJ, Hamsten A, Bedford D, Caslake M, Foster L, Shepherd J, Stewart P \& Karpe F (1996) Accumulation of large very low density lipoprotein in plasma during venous infusion of a chylomicron-like emulsion reflects competition for a common lipolytic pathway. Journal of Lipid Research 37, 76-86.

Björntorp B, Fahlén M, Grimby G, Gustafson A, Holm J, Renström P \& Scherstén T (1972) Carbohydrate and lipid metabolism in middle-aged, physically well-trained men. Metabolism 21, 1037-1044.

Borensztajn J, Rone MS, Babirak SP, McGarr JA \& Oscai LB (1975) Effect of exercise on lipoprotein lipase activity in rat heart and skeletal muscle. American Journal of Physiology 229, 394-397.

Cohen H \& Goldberg C (1960) Effect of physical exercise on alimentary lipaemia. British Medical Journal 2, 509-511.

Cohen JC, Noakes TD \& Benade AJS (1989) Postprandial lipemia and chylomicron clearance in athletes and sedentary men. American Journal of Clinical Nutrition 49, 443-447.

Costill DL, Fink WJ \& Pollock ML (1976) Muscle fibre composition and enzyme activities of elite distance runners. Medicine and Science in Sports and Exercise 8, 96-100.

Costill DL, Gollnick PD, Jansson ED, Saltin B \& Stein EM (1973) Glycogen depletion pattern in human muscle fibres during distance running. Acta Physiologica Scandinavica 89, 374383.

Dela F, Mikines KJ, von Linstow M, Secher NH \& Galbo H (1992) Effect of training on insulin-mediated glucose uptake in human muscle. American Journal of Physiology 263, E1134 E1143.

Drexel H, Pfister R, Mitterbauer G, Föger BH, Lechleitner M, Hörtnagl H \& Patsch JR (1992) Postprandial lipid and glucose metabolism in women undergoing moderate weight loss by diet plus exercise. Nutrition, Metabolism and Cardiovascular Diseases 2, 159-164.

Dufaux B, Assman G, Order U, Hoederath A \& Hollmann W (1981) Plasma lipoproteins, hormones, and energy substrates during the first days after prolonged exercise. International Journal of Sports Medicine 2, 256-260.

Dustine JL \& Haskell WL (1994) Effects of exercise training on plasma lipids and lipoproteins. Exercise and Sport Science Reviews 22, 477-521.

Ebeling P, Bourey R, Koranyi L, Tuominen JA, Groop LC, Henriksson J, Mueckler M, Sovijäri A \& Koivisto VA (1993) Mechanism of enhanced insulin sensitivity in athletes. Increased blood flow, muscle glucose transport protein (GLUT-4) concentration, and glycogen synthase activity. Journal of Clinical Investigation 92, 1623-1631.
Eckel RH (1989) Lipoprotein lipase: A multifactorial enzyme relevant to common metabolic diseases. New England Journal of Medicine 320, 1060-1067.

Ericsson M, Johnson O, Tollin C, Furberg B, Backman C \& Ängquist K (1982) Serum lipoproteins, apolipoproteins and intravenous fat tolerance in young athletes. Scandinavian Journal of Rehabilitation Medicine 14, 209-212.

Essén B (1978) Studies on the regulation of metabolism in human skeletal muscle using intermittent exercise as an experimental model. Acta Physiologica Scandinavica 454, Suppl., 1-32.

Farese RV, Yost TJ \& Eckel RH (1991) Tissue-specific regulation of lipoprotein lipase activity by insulin/glucose in normalweight humans. Metabolism 40, 214-216.

Fröberg SO, Carlson LA \& Ekelund LG (1971) Local lipid stores and exercise. In Muscle Metabolism During Exercise, pp. 307-313 [B Pernow and B Saltin, editors]. New York: Plenum Press.

Fröberg SO \& Mossfeldt F (1971) Effect of prolonged strenuous exercise on the concentrations of triglycerides, phospholipids and glycogen in muscle of man. Acta Physiologica Scandinavica 82, 167-171.

Griffiths AJ, Humphreys SM, Clark ML \& Frayn KN (1994) Forearm substrate utilization during exercise after a meal containing both fat and carbohydrate. Clinical Science 86, 169 175.

Hardman AE \& Aldred HE (1995) Walking during the postprandial period decreases alimentary lipaemia. Journal of Cardiovascular Risk 2, 71-78.

Hartung H, Lawrence SJ, Reeves RS \& Foreyt JP (1993) Effect of alcohol and exercise on postprandial lipemia and triglyceride clearance in men. Atherosclerosis 100, 33-40.

Havel RJ, Pernow B \& Jones NL (1967) Uptake and release of fatty acids and other metabolites in the legs of exercising men. Journal of Applied Physiology 23, 90-99.

Hurley BF, Nemeth PM, Martin WH, Hagberg JM, Dalsky DP \& Holloszy JO (1986) Muscle triglyceride utilization during exercise; effect of training. Journal of Applied Physiology 60, $562-567$.

Ingjer F (1979) Effects of endurance training on muscle fibre ATP-ase activity, capillary supply and mitochondrial content in man. Journal of Physiology 294, 419-432.

Isherwood SG (1996) Apolipoprotein B-48 as a marker for chylomicrons and their remnants. PhD Thesis, University of Surrey.

Jacobs I, Lithell H \& Karlsson J (1982) Dietary effects on glycogen and lipoprotein lipase activity in skeletal muscle in man. Acta Physiologica Scandinavica 115, 85-90.

Jansson E \& Kaijser L (1982) Effect of diet on the utilization of blood-borne and intramuscular substrates during exercise in man. Acta Physiologica Scandinavica 115, 19-30.

Kaijser L \& Rössner S (1975) Removal of exogenous triglycerides in human forearm muscle and subcutaneous tissue. Acta Medica Scandinavica 197, 289-294.

Kantor MA, Cullinane EM, Herbert PN \& Thompson PD (1984) Acute increase in lipoprotein lipase following prolonged exercise. Metabolism 33, 454-457.

Kantor MA, Cullinane EM, Sady SP, Herbert PN \& Thompson PD (1987) Exercise acutely increases high density lipoproteincholesterol and lipoprotein lipase activity in trained and untrained men. Metabolism 36, 188-192.

Kiens B, Essén-Gustavsson B, Christensen JJ \& Saltin B (1993) Skeletal muscle substrate utilization during submaximal exercise in man: effect of endurance training. Journal of Physiology 469, 459-478.

Kiens B \& Lithell H (1989) Lipoprotein metabolism influenced by training-induced changes in human skeletal muscle. Journal of Clinical Investigation 83, 558-564. 
Kiens B, Lithell H, Mikines KJ \& Richter E (1989) Effects of insulin and exercise on muscle lipoprotein lipase activity in man and its relation to insulin action. Journal of Clinical Investigation 84, 1124-1129.

Klein L, Miller TD, Radam TE, O'Brien T, Nguyen TT \& Kottke BA (1992) Acute physical exercise alters apolipoprotein $\mathrm{E}$ and C-III concentrations of apo E-rich very low density lipoprotein fraction. Atherosclerosis 97, 37-51.

Lamarche B, Després JP, Moorjani S, Nadeau A, Lupien PJ, Tremblay A, Thériault G \& Bouchard C (1993) Evidence for a role of insulin in the regulation of abdominal adipose tissue lipoprotein lipase response to exercise training in obese women. International Journal of Obesity 17, 255-261.

Lawrence JEM, Herd SL, Hardman AE \& Harrison M (1997). Influence of a short period of de-training on postprandial lipaemia and insulinaemia in endurance-trained individuals. Proceedings of the Nutrition Society 56, 286A.

Lee DJ, Aldred HE \& Hardman AE (1993) Postprandial lipaemia in young endurance and sprint trained men and women. Clinical Science 84, 9.

Lithell H, Cedermark M, Fröberg J, Tesch P \& Karlsson J (1981) Increase of lipoprotein-lipase activity in skeletal muscle during heavy exercise. Relation to epinephrine excretion. Metabolism 30, 1130-1134.

Lithell H, Hellsing K, Lundqvist G \& Malmberg P (1979a) Lipoprotein-lipase activity of human skeletal-muscle and adipose tissue after intensive physical exercise. Acta Physiologica Scandinavica 105, 312-315.

Lithell H, Örlander J, Schéle R, Sjödin B \& Karlsson J (1979b) Changes in lipoprotein-lipase activity and lipid stores in human skeletal muscle with prolonged heavy exercise. Acta Physiologica Scandinavica 107, 257-261.

McDonald GA \& Fullerton HW (1960) Effect of phenindione and bed rest on blood coagulability following a high-fat intake Lancet ii, $1111-1112$.

Mankowitz K, Seip R, Semenkovich CF, Daugherty A \& Schonfeld G (1992) Short-term interruption of training affects both fasting and post-prandial lipoproteins. Atherosclerosis $\mathbf{9 5}$, 181-189.

Marniemi J, Peltonen P, Vuori I \& Hietanen E (1980) Lipoprotein lipase of human postheparin plasma and adipose tissue in relation to physical training. Acta Physiologica Scandinavica 110, 131-135.

Merrill JR, Holly RG, Anderson RL, Rifai N, King ME \& DeMeersman R (1989) Hyperlipemic response of young trained and untrained men after a high fat meal. Arteriosclerosis 9, 217-223.

Nagel D, Seiler D, Franz H, Leitzmann C \& Jung K (1989) Effects of an ultra-long-distance $(1000 \mathrm{~km})$ race on lipid metabolism. European Journal of Applied Physiology 59, 1620.

Newsholme EA \& Leech AR (1994) Biochemistry for the Medical Sciences. Chichester: John Wiley and Sons.

Nguyen TT, Hernández M, Johnson CM \& Jensen MD (1996) Postprandial leg and splanchnic fatty acid metabolism in nonobese men and women. American Journal of Physiology 271, E965-E972.

Nikkilä EA (1987) Role of lipoprotein lipase in metabolic adaptation to exercise and training. In Lipoprotein Lipase, pp. 187-199 [J Borensztajn, editor]. Chicago, IL: Evener.

Nikkilä EA \& Konttinen A (1962) Effect of physical activity on postprandial levels of fats in serum. Lancet ii, 1151154.

Nikkilä EA, Taskinen MR, Rehunen S \& Härkönen M (1978) Lipoprotein lipase activity in adipose tissue and skeletal muscle of runners: Relation to serum lipoproteins. Metabolism 27, 1661-1671.
O'Meara NM, Lewis GF, Cabana VG, Iverius PH, Getz GS \& Polonsky KS (1992) Role of basal triglyceride and high density lipoprotein in determination of postprandial lipid and lipoprotein responses. Journal of Clinical Endocrinology and Metabolism 75, 465-471.

Olsson AG, Eklund B, Kaijser L \& Carlson LA (1975) Extraction of endogenous plasma triglycerides by the working human forearm muscle in the fasting state. Journal of Clinical and Laboratory Investigation 35, 231-236.

Patsch JR, Karlin JB, Scott LW, Smith LC \& Gotto AM (1983) Inverse relationship between blood levels of high density lipoprotein subfraction 2 and magnitude of postprandial lipemia. Proceedings of the National Academy of Sciences USA 80, 1449-1453.

Patsch JR, Miesenböck G, Hopferwieser T, Muhlberger V, Knapp E, Dunn JK, Gotto AM \& Patsch W (1992) Relation of triglyceride metabolism and coronary artery disease. Studies in the postprandial state. Arteriosclerosis and Thrombosis 12, 1336-1345.

Peltonen P, Marniemi J, Hietanen E, Vuori I \& Ehnholm C (1981) Changes in serum lipids, lipoproteins, and heparin releasable lipolytic enzymes during moderate physical training in man: A longitudinal study. Metabolism 30, 518-526.

Podl TR, Zmuda JM, Yurgalevitch SM, Fahrenhach MC, Bausserman LL, Terry RB \& Thompson PD (1994) Lipoprotein lipase activity and plasma triglyceride clearance are elevated in endurance-trained women. Metabolism 43, 808-813.

Potts JL, Fisher RM, Humphreys SM, Coppack SW, Gibbons G \& Frayn KN (1991a) Chylomicrons are the preferred substrate for lipoprotein lipase in vivo. Biochemical Society Transactions 19, 314 S.

Potts J, Fisher RM, Humphreys SM, Coppack SW, Gibbons GF \& Frayn KN (1991b) Peripheral triacylglycerol extraction in the fasting and post-prandial states. Clinical Science 81, 621626.

Romijn JA, Coyle EF, Sidossis LS, Gastaldelli A, Horowitz JF, Endert E \& Wolfe RR (1993) Regulation of endogenous fat and carbohydrate metabolism in relation to exercise intensity and duration. American Joumal of Physiology 265, E380E391.

Rössner S (1974) Studies on an intrvenous fat tolerance test: methodological, experimental and clinical experiences with Intralipid. Acta Medica Scandinavica 564, Suppl., 3-24.

Rowell LB (1993) Human Cardiovascular Control. New York and Oxford: Oxford University Press.

Ruys T, Sturgess I, Shaikh M, Watts GF, Nordestgaard BG \& Lewis B (1987) Effects of exercise and fat ingestion on high density lipoprotein production by peripheral tissues. Lancet ii, $1119-1122$.

Sady SP, Cullinane EM, Saritelli A, Bernier D \& Thompson PD (1988) Elevated high-density lipoprotein cholesterol in endurance athletes is related to enhanced plasma triglyceride clearance. Metabolism 37, 568-572.

Sady SP, Thompson PD, Cullinane EM, Kantor MA, Domagala E \& Herbert PN (1986) Prolonged exercise augments plasma triglyceride clearance. Journal of the American Medical Association 256, 2552-2555.

Saggerson D, Ghadiminejad I \& Awan M (1992) Regulation of mitochondrial carnitine palmitoyl transferase from liver and extrahepatic tissues. Advances in Enzyme Regulation 32, 285306.

Saltin B \& Åstrand PO (1993) Free fatty acids and exercise. American Journal of Clinical Nutrition 57, Suppl., 75S-78S.

Schlierf G, Dinsenbacher A, Kather H, Kohlmeier M \& Haberbosch W (1987) Mitigation of alimentary lipemia by postprandial exercise: Phenomena and mechanisms. Metabolism 36, 726-730. 
Seip RL, Angelopoulos TJ \& Semenkovich CF (1995) Exercise induces human lipoprotein lipase gene expression in skeletal muscle but not adipose tissue. American Journal of Physiology 31, E229-E236.

Seip RL, Mair K, Cole TG \& Semenkovich CF (1997) Induction of human skeletal muscle lipoprotein lipase gene expression by short-term exercise is transient. American Journal of Physiology 272, E255-E261.

Simsolo RB, Ong JM \& Kern PA (1993) The regulation of adipose tissue and muscle lipoprotein lipase in runners by detraining. Journal of Clinical Investigation 92, 2124-2130.

Sniderman AD \& Cianflone K (1993) Substrate delivery as a determinant of hepatic apoB secretion. Arteriosclerosis and Thrombosis 13, 629-636.

Soffer EE, Summers RW \& Gisolfi C (1991) Effect of exercise on intestinal motility and transit in trained athletes. American Journal of Physiology 260, G698-G702.

Svedenhag J, Lithell H, Juhlin-Dannfelt A \& Henriksson J (1983) Increase in skeletal muscle lipoprotein lipase following endurance training in man. Atherosclerosis 49, 203-207.

Tan MH, Sata T \& Havel RJ (1977) The significance of lipoprotein lipase in rat skeletal muscles. Journal of Lipid Research 18, 363-370.

Taskinen MR, Nikkilä ES, Rehunen S \& Gordin A (1980) Effect of acute vigorous exercise on lipoprotein lipase activity of adipose tissue and skeletal muscle in physically active men. Artery 6, 471-483.

Terjung RL, Mackie BC, Dudley GA \& Kaciuba-Uscilko H (1983) Influence of exercise on chylomicron triacylglycerol metabolism: plasma turnover and muscle uptake. Medicine and Science in Sports and Exercise 15, 340-347.

Tesch P, Thorsson A \& Kaiser P (1984) Muscle capillary supply and fiber type characteristics in weight and power lifters. Journal of Applied Physiology 56, 35-38.

Thompson PD, Cullinane EM, Sady SP, Glynn MM, Bernier DN, Kantor MA, Saritelli AL \& Herbert PN (1988) Modest changes in high-density lipoprotein concentration and metabolism with prolonged exercise training. Circulation 78, 25-34.

Tsetsonis NV \& Hardman AE (1996) Reduction in postprandial lipemia after walking: influence of exercise intensity. Medicine and Science in Sports and Exercise 28, 12351242.

Tsetsonis NV, Hardman AE \& Mastana SS (1997) Acute effects of exercise on postprandial lipemia: a comparative study in trained and untrained middle-aged women. American Journal of Clinical Nutrition 65, 525- 533.

Turcotte LP, Richter EA \& Kiens B (1995) Lipid metabolism during exercise. In Exercise Metabolism, pp. 99-130 [M Hargreaves, editor]. Champaign, IL: Human Kinetics.

van der Vusse GJ \& Reneman RS (1996) Lipid metabolism in muscle. In Handbook of Physiology, pp. 1036-1074 [LB Rowell and JT Shepherd, editors]. New York: Oxford University Press.

Walker M (1986) Dietary planning for performance. In Nutrition in Sport, pp. 50-63 [DH Shrimpton and P Berry Ottaway, editors]. London: Central Council for Physical Recreation.

Weintraub MS, Rosen Y, Otto R, Eisenberg S \& Breslow JL (1989) Physical conditioning in the absence of weight loss reduces fasting and postprandial triglyceride-rich lipoprotein levels. Circulation 79, 1007-1014.

Wirth A, Diehm C, Hanel W, Welte J \& Vogel I (1985) Traininginduced changes in lipids, fat tolerance and adipose tissue metabolism in patients with hypertriglyceridemia. Atherosclerosis 54, 263-271.

Yanes AM, Holly RG, Schneeman BO \& Amsterdam EA (1989) Effect of cardiac rehabilitation on postprandial response to a high fat meal in patients with coronary artery disease. Atherosclerosis 78, 1-8.

Zauner CW \& Benson NY (1977) Effect of physical training upon postprandial lipemia in men with abnormal responses to the oral fat tolerance test. Journal of Sports Medicine 17, 381386. 